\title{
Effect of Radiation on Chiasma Frequency in Sunflower (Helianthus annuus)
}

\author{
S. M. Al-Allaf and M. B. E. Godward \\ Department of Plant Biology and Microbiology, Queen Mary College, \\ University of London, Mile End Road, London, El 4NS. U. K.
}

Received February 21, 1978

In the literature, increase, decrease, and no change in chiasma frequency following radiation treatment, have all been reported by many authors in a variety of organisms. Sometimes, in the same organism, reports by different authors are contradictory. For instance, in Vicia faba Mather (1934) found an increase, Marquardt (Marquardt 1951) found a decrease. In Tradescantia bracteata, an increase was recorded by Mather (Mather 1934) and a decrease by Darlington and La Cour (Darlington and $\mathrm{La}$ Cour 1953). In Lilium regale, Darlington and $\mathrm{La}$ Cour (Darlington and La Cour 1953) found an increase.

Lawrence in Tradescantia paludosa (Lawrence 1961) claimed two sensitive stages following irradiation; late pre-leptotene giving a slight decrease and late zygotene-early pachytene, giving an increase. Similar observations were made on Lilium longiflorum by Lawrence (Lawrence 1961) who reported a marked drop in chiasma frequency when irradiating just before the start of meiosis, and an increase when irradiation was at late zygotene-early pachytene and at late diplotene. In Crotalaria intermedia, some tendency towards a decrease in chiasma frequency has been reported (Sybenga 1960).

However, all these previous reports have dealt with the immediate effects of radiation since it was the flower buds that were subjected to the radiation treatments. In the last ten years, reports have been coming in following treatment of dry seeds with radiation or chemical mutagens. Most of these reports claim reduction of chiasma frequency, for example, in Pisum sativum (Gottschalk and Villalobos-Pietrini 1965; Joshi and Chauhan 1973), in Delphinium ajacis (Jain and Basak 1965), in Lens culinaris (Sinha and Godward 1969), in Phalaris canariensis and P. minor (Prasad and Godward 1969) in Sorghum subglabrascens and S. durra (Ramulu 1971) and in Sorghum pupureosericeum (Ramulu 1973).

The present investigation undertaken in Helianthus annuus allows us to determine variental responses, in particular following seed irradiation of commercial varieties, in an organism with a high number of small chromosomes and a symmetrical karyotype.

\section{Material and methods}

Seeds air-dried by a standardised procedure (water content was also determined) of three commercial varieties of sunflower (Helianthus annuus) $2 \mathrm{n}=34$ were exposed to different doses of gamma radiation. These varieties are designated 
as follows: Iraqui local variety, $\mathrm{HI}$; Bulgarian variety, $\mathrm{HB}$ : and Rumanian variety, HR. Permanent slides at different doses and controls, prepared for meiotic study and showing full diakinesis, were used to score chiasma frequencies. Five plants were included in each treatment. All the anthers of three florets represent each plant; ten to twenty cells were scored from each slide.

Scoring of chiasma frequency was performed only on very clear pollen mother cells showing well separated bivalents (Fig. 2).

\section{Statistical analysis}

A method described by Mather (Mather $1943 \mathrm{pp}$. 168-173) for the analysis of variance has been used. The seventeen bivalents of $H$. annuus cannot be distinguished from one another due to the similarity in size of the chromosomes. The analysis of variance is of necessity incomplete (Mather and Lamm 1935).

\section{Results}

Scoring and analysis of chiasma frequencies at various doses of radiation and in untreated controls are presented in Table 1 and Fig. 3.

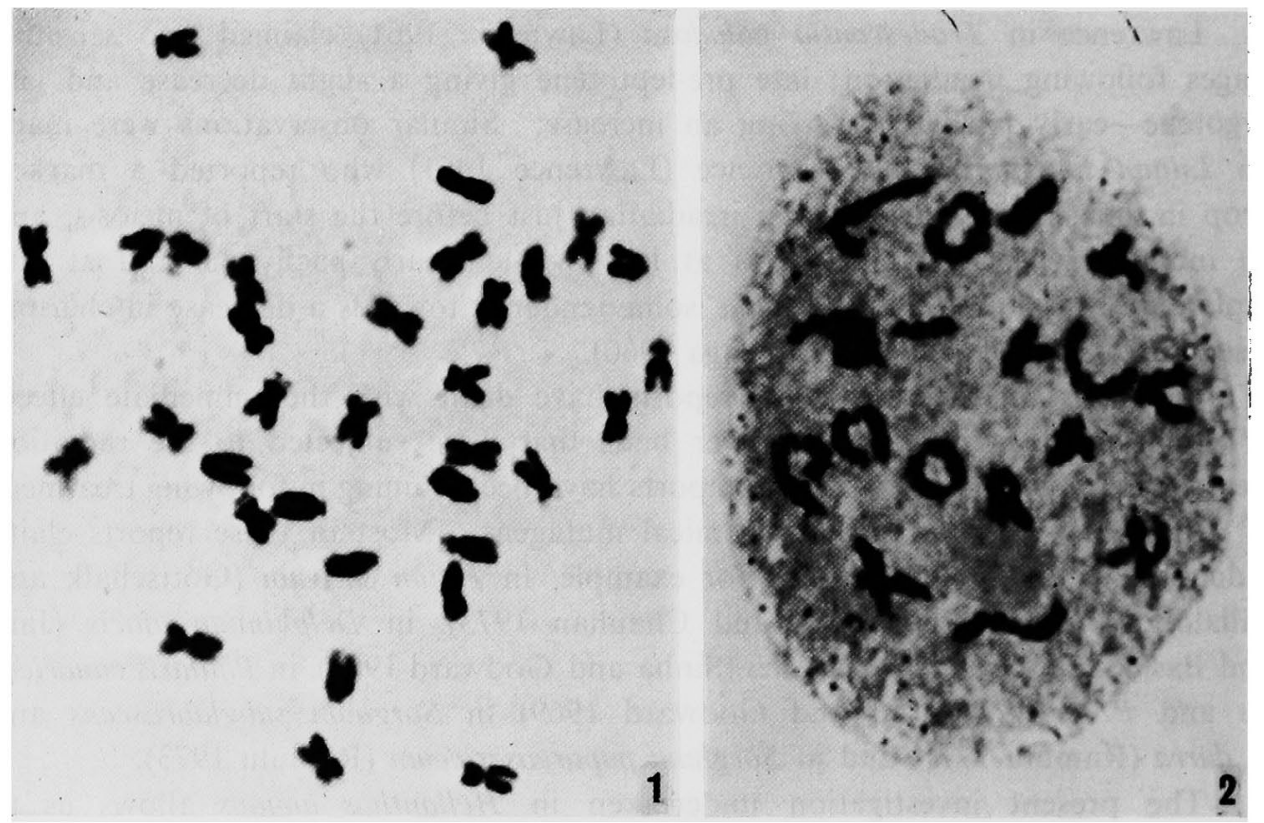

Figs. 1-2. 1, H. annuus, diploid cell with 34 chromosomes. $\times 3000.2, H$. annuus, pollen mother cell at diakinesis. $\times 3000$.

In the controls, it can be seen that the number of chiasmata per nucleus varies from 26.98 in $\mathrm{HR}$ to 25.86 in $\mathrm{HB}$. $\mathrm{HI}$ is in an inter-mediate position and gave the value 26.09 , which is rather near to that of the HB variety.

The number of chiasmata per bivalent showed the same trend as that per nucleus. The highest value, 1.59 occurred in HR; the lowest, 1.52 in HB. HI, 1.53 , is intermediate. However, the mean chiasma frequency per nucleus and 
per bivalent in the three varieties examined in this study was found to be higher than that perviously reported (Georgieva-Todorova 1972) in a Russian variety, in which chiasma frequencies of 23.88 and 1.40 per nucleus and per bivalent respectively were found.

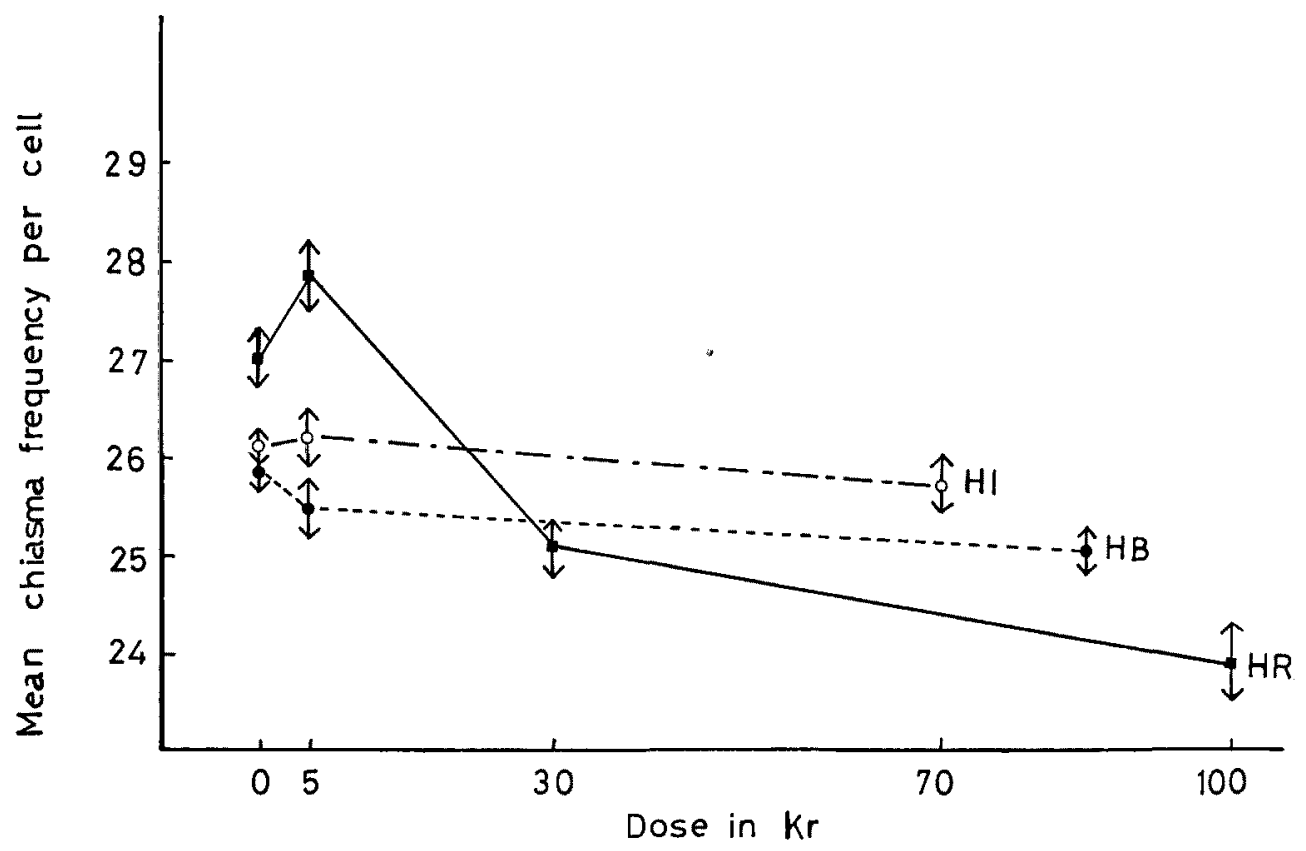

Fig. 3. Mean chiasma frequency per cell.

The distribution histograms of the mean chiasma freqency per nucleus for each dose and their respective controls in the three varieties of the present work have been plotted (Fig. 4). In general these histograms show clear differences between the controls of the three varieties. $H R$ and $H B$ are widely spread, the ranges are 22-32 and 20-32 respectively. HR has a broad peak between 26 and 28; HB has a gradual rise to a peak at 27. The HI control provides a different, more compact distribution; the number of chiasma per nucleus ranging between 22-30, with high percentages of the nuclei clustered around the mean showing a clear high peak at 26. This different behaviour of the control in the variety $\mathrm{HI}$ will be discussed later.

Differences between varieties also exist with respect to the distribution of chiasma between the bivalents (Table 3). The controls of HR and HI show a maximum number of bivalents with two chiasmata, whereas in HB the maximum number of bivalents is with one chiasma only. However, in all varieties most bivalents have one or two chiasmata, a small proportion has three, and there are one or two occasional bivalents with four in HB. One bivalent is also noticed with four chiasmata in $\mathrm{HI}$, there is none in HR.

In comparing the results of irradiated populations with their respective controls, as can be seen from Table 1 and Fig. 3, differential varietal response 

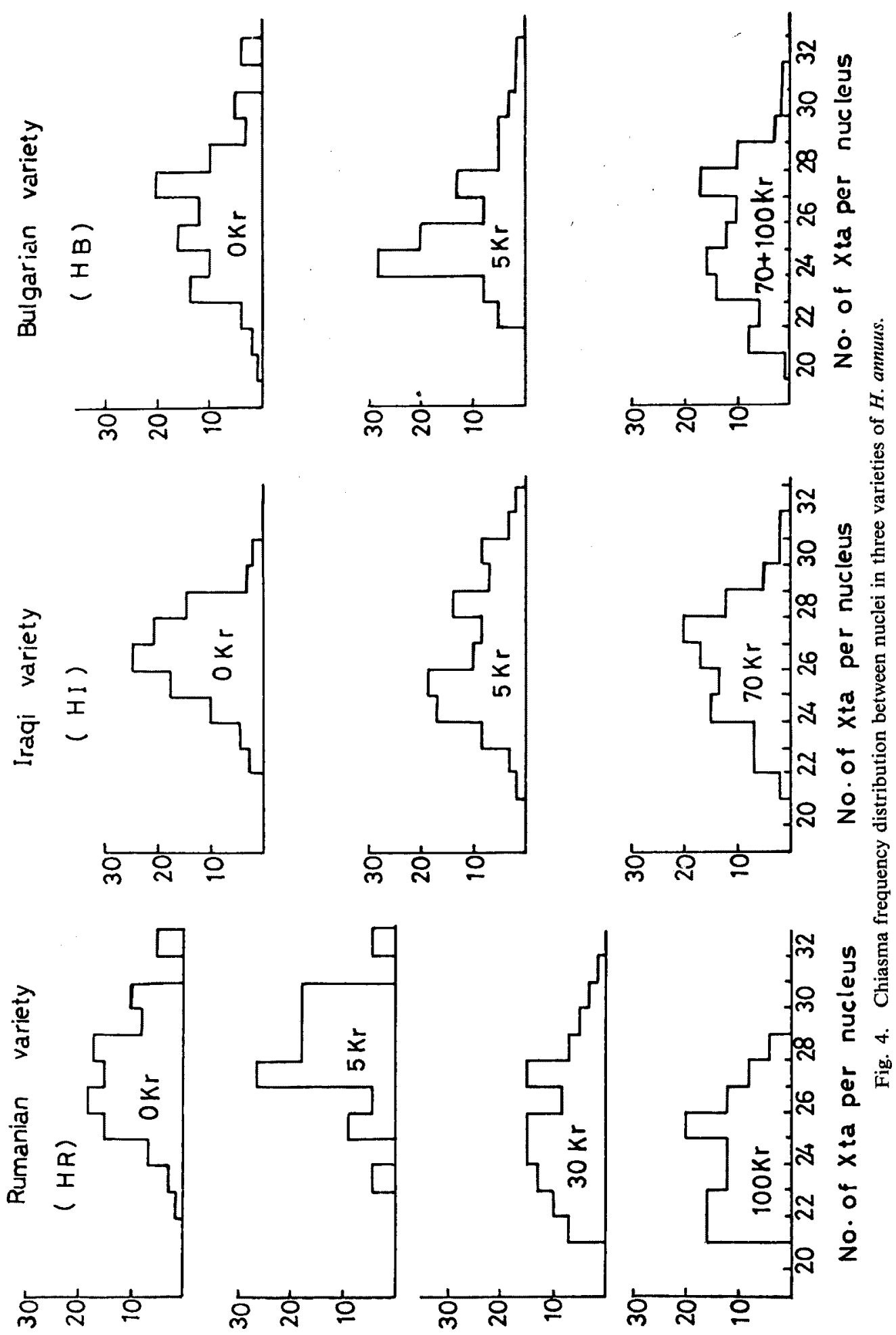

$\%$ ! 
to radiation is found. HR which is the most sensitive variety (with regard to other characters not reported here) registered a drop in the mean chiasma frequency per nucleus at high doses. The significance of this is demonstrated by the " $t$ " test (Table 4) which is significant at the $1 \%$ level, thus indicating a genuine difference between the means. A similar trend towards reduced chiasma frequency following radiation in the other two varieties is also noticed, but it is not significant as indicated by the " $t$ "' test. However, when the two high doses, $70 \mathrm{Kr}$ and $100 \mathrm{Kr}$ in the variety $\mathrm{HB}$ are grouped together, the pooled mean versus the control reached the $5 \%$ level of significance.

The regression line for chiasma frequency on dose is very steep in variety HR (Fig. 5) where $\mathrm{r}$ is negative and significant at $5 \%$ level. A slight slope is seen in the variety $\mathrm{HI}$ and variety $\mathrm{HB}$ after pooling the high doses. However, in spite of the fact that varieties HI and HB showed no significant reduction in the mean chiasma frequency following radiation, a trend in this direction is

Table 1. Analysis of variance of chiasma frequency at diakinesis

\begin{tabular}{|c|c|c|c|c|c|c|c|c|c|c|}
\hline \multicolumn{11}{|c|}{ Rumanian variety (HR) } \\
\hline \multirow{3}{*}{$\begin{array}{l}\text { Treat- } \\
\text { ments }\end{array}$} & \multirow{3}{*}{$\begin{array}{l}\text { No. of } \\
\text { cells } \\
\text { scored }\end{array}$} & \multirow{3}{*}{$\begin{array}{l}\text { Mean } \\
\text { no. of } \\
\text { Xta per } \\
\text { nucleus }\end{array}$} & \multirow{3}{*}{$\begin{array}{c}\text { Mean } \\
\text { no. of } \\
\text { Xta per } \\
\text { bi- } \\
\text { valent }\end{array}$} & \multicolumn{4}{|c|}{ Source of variation } & \multirow{3}{*}{$\begin{array}{l}\text { Variance } \\
\text { ratio }\end{array}$} & \multirow{3}{*}{\multicolumn{2}{|c|}{$\begin{array}{l}\text { Corre- } \\
\text { lation }\end{array}$}} \\
\hline & & & & \multicolumn{2}{|c|}{ between nuclei } & \multicolumn{2}{|c|}{ within nuclei } & & & \\
\hline & & & & MS & $\mathrm{df}$ & MS & df & & & \\
\hline Control & 60 & $\begin{array}{l}26.98 \\
\pm 0.29\end{array}$ & 1.59 & 0.2981 & 59 & 0.2663 & 960 & 1.1194 & + & $\div$ \\
\hline $5 \mathrm{Kr}$ & 23 & $\begin{array}{l}27.87 \\
\pm 0.42\end{array}$ & 1.64 & 0.2369 & 22 & 0.2743 & 386 & 1.1579 & - & $\div$ \\
\hline $30 \mathrm{Kr}$ & 60 & $\begin{array}{l}25.07 \\
\pm 0.32\end{array}$ & 1.47 & 0.3686 & 59 & 0.2652 & 960 & 1.3899 & + & * \\
\hline $100 \mathrm{Kr}$ & 25 & $\begin{array}{l}23.92 \\
\pm 0.42\end{array}$ & 1.41 & 0.2594 & 24 & 0.2409 & 400 & 1.0768 & + & $\div$ \\
\hline \multicolumn{11}{|c|}{ Iraqi variety $(\mathrm{HI})$} \\
\hline Control & 90 & $\begin{array}{l}26.09 \\
\pm 0.18\end{array}$ & 1.53 & 0.1648 & 89 & 0.2903 & 1440 & 1.7615 & - & * \\
\hline $5 \mathrm{Kr}$ & 60 & $\begin{array}{l}26.17 \\
\pm 0.33\end{array}$ & 1.54 & 0.3892 & 59 & 0.2776 & 960 & 1.4020 & + & * \\
\hline $70 \mathrm{Kr}$ & 60 & $\begin{array}{l}25.75 \\
\pm 0.28\end{array}$ & 1.51 & 0.2724 & 59 & 0.2653 & 960 & 1.0268 & + & $\div$ \\
\hline \multicolumn{11}{|c|}{ Bulgarian variety $(\mathrm{HB})$} \\
\hline Control & 100 & $\begin{array}{l}25.86 \\
\pm 0.25\end{array}$ & 1.52 & 0.3755 & 99 & 0.3119 & 1600 & 1.2039 & + & $\div$ \\
\hline $5 \mathrm{Kr}$ & 60 & $\begin{array}{l}25.48 \\
\pm 0.29\end{array}$ & 1.50 & 0.2961 & 59 & 0.2828 & 960 & 1.0470 & + & $\div$ \\
\hline $\begin{array}{l}70 \mathrm{Kr}+ \\
100 \mathrm{Kr} \\
\text { (pooled) }\end{array}$ & 120 & $\begin{array}{l}25.06 \\
25.06 \\
\pm 0.22\end{array}$ & 1.47 & 0.3562 & 119 & 0.2803 & 1920 & 1.2707 & + & $*$ \\
\hline
\end{tabular}

$\div=$ not significant

* $=$ significant at $5 \%$ level 
Table 2. Chiasma frequency distribution between nuclei at different doses and controls in three varieties

\begin{tabular}{|c|c|c|c|c|c|c|c|c|c|c|c|c|c|c|}
\hline \multicolumn{15}{|c|}{ Rumanian variety (HR) } \\
\hline \multirow{2}{*}{$\begin{array}{l}\text { Treat- } \\
\text { ments }\end{array}$} & \multirow{2}{*}{$\begin{array}{l}\text { Number } \\
\text { of } \\
\text { cells ex- } \\
\text { amined }\end{array}$} & \multicolumn{13}{|c|}{$\%$ of nuclei with different numbers of $\mathrm{Xta}$} \\
\hline & & 20 & 21 & 22 & 23 & 24 & 25 & 26 & 27 & 28 & 29 & 30 & 31 & 32 \\
\hline $0 \mathrm{Kr}$ & 60 & - & - & 1.7 & 3.3 & 6.7 & 15 & 18.3 & 15 & 16.7 & 8.3 & 10 & - & 5 \\
\hline $5 \mathrm{Kr}$ & 23 & - & - & - & 4.4 & - & 8.7 & 4.3 & 26.1 & 17.4 & 17.4 & 17.4 & 一 & 4.3 \\
\hline $30 \mathrm{Kr}$ & 60 & - & 6.7 & 10 & 13.3 & 15 & 15 & 8.3 & 15 & 6.7 & 5 & 3.3 & 1.7 & - \\
\hline $100 \mathrm{Kr}$ & 25 & - & 16 & 16 & 12 & 12 & 20 & 12 & 8 & 4 & - & - & - & - \\
\hline \multicolumn{15}{|c|}{ Iraqi variety $(\mathrm{HI})$} \\
\hline $0 \mathrm{Kr}$ & 90 & - & - & 2.2 & 4.5 & 10 & 17.8 & 24.5 & 21.1 & 14.4 & 3.3 & 2.2 & - & - \\
\hline $5 \mathrm{Kr}$ & 60 & - & 1.7 & 3.3 & 8.3 & 16.7 & 18.3 & 10 & 8.3 & 13.3 & 6.7 & 8.3 & 3.3 & 1.7 \\
\hline $70 \mathrm{Kr}$ & 60 & - & 1.7 & 6.6 & 6.6 & 15 & 13.3 & 16.7 & 20 & 11.7 & 5 & 1.7 & 1.7 & - \\
\hline \multicolumn{15}{|c|}{ Bulgarian variety $(\mathrm{HB})$} \\
\hline $0 \mathrm{Kr}$ & 100 & 1 & 2 & 4 & 13 & 10 & 16 & 12 & 20 & 10 & 3 & 5 & - & 4 \\
\hline $5 \mathrm{Kr}$ & 60 & - & - & 5 & 8.3 & 28.3 & 13.3 & 8.3 & 13.3 & 5 & 5 & 3.3 & 1.7 & 1.7 \\
\hline \multicolumn{15}{|l|}{ Pooled } \\
\hline $\begin{array}{c}70 \mathrm{Kr}+ \\
100 \mathrm{Kr}\end{array}$ & 120 & 0.8 & 8.3 & 5.8 & 14.2 & 15.8 & 11.7 & 10 & 16.7 & 10 & 3.3 & 1.7 & 1.7 & - \\
\hline
\end{tabular}

Table 3. Chiasma frequency distribution between bivalents at different doses and controls in three varieties of $H$. annuus

\begin{tabular}{|c|c|c|c|c|c|}
\hline \multicolumn{6}{|c|}{ Rumanian variety (HR) } \\
\hline \multirow{2}{*}{ Treatments } & \multirow{2}{*}{$\begin{array}{l}\text { Number } \\
\text { of cells } \\
\text { examined }\end{array}$} & \multicolumn{4}{|c|}{$\%$ of bivalents with different numbers of $\mathrm{Xta}$} \\
\hline & & $1 \mathrm{Xta}$ & $2 \mathrm{Xta}$ & $3 \mathrm{Xta}$ & $4 \mathrm{Xta}$ \\
\hline $\mathrm{OKr}$ & 60 & 42.55 & 56.18 & 1.27 & - \\
\hline $5 \mathrm{Kr}$ & 23 & 38.11 & 59.85 & 2.04 & - \\
\hline $30 \mathrm{Kr}$ & 60 & 53.63 & 45.29 & 1.08 & - \\
\hline $100 \mathrm{Kr}$ & 25 & 59.29 & 40.71 & - & - \\
\hline \multicolumn{6}{|c|}{ Iraqi variety $(\mathrm{HI})$} \\
\hline $\mathrm{OKr}$ & 90 & 48.17 & 50.26 & 1.50 & 0.07 \\
\hline $5 \mathrm{Kr}$ & 60 & 47.84 & 50.39 & 1.77 & - \\
\hline $70 \mathrm{Kr}$ & 60 & 49.31 & 49.90 & 0.79 & - \\
\hline \multicolumn{6}{|c|}{ Bulgarian variety (HB) } \\
\hline $0 \mathrm{Kr}$ & 100 & 51.06 & 45.88 & 2.94 & 0.12 \\
\hline $5 \mathrm{Kr}$ & 60 & 51.67 & 46.86 & 1.37 & 0.10 \\
\hline $70 \mathrm{Kr}$ & 60 & 57.45 & 41.27 & 1.18 & 0.10 \\
\hline \multicolumn{6}{|l|}{ Pooled } \\
\hline $\begin{array}{c}70 \mathrm{Kr}+ \\
100 \mathrm{Kr}\end{array}$ & 120 & 54.2 & 44.2 & 1.5 & 0.10 \\
\hline
\end{tabular}

The peak number of Xta per bivalent at each dose is expressed in bold faced type. 
Table 4. Mean number of chiasmata per cell at each dose versus control ( $\mathrm{t}$ - test)

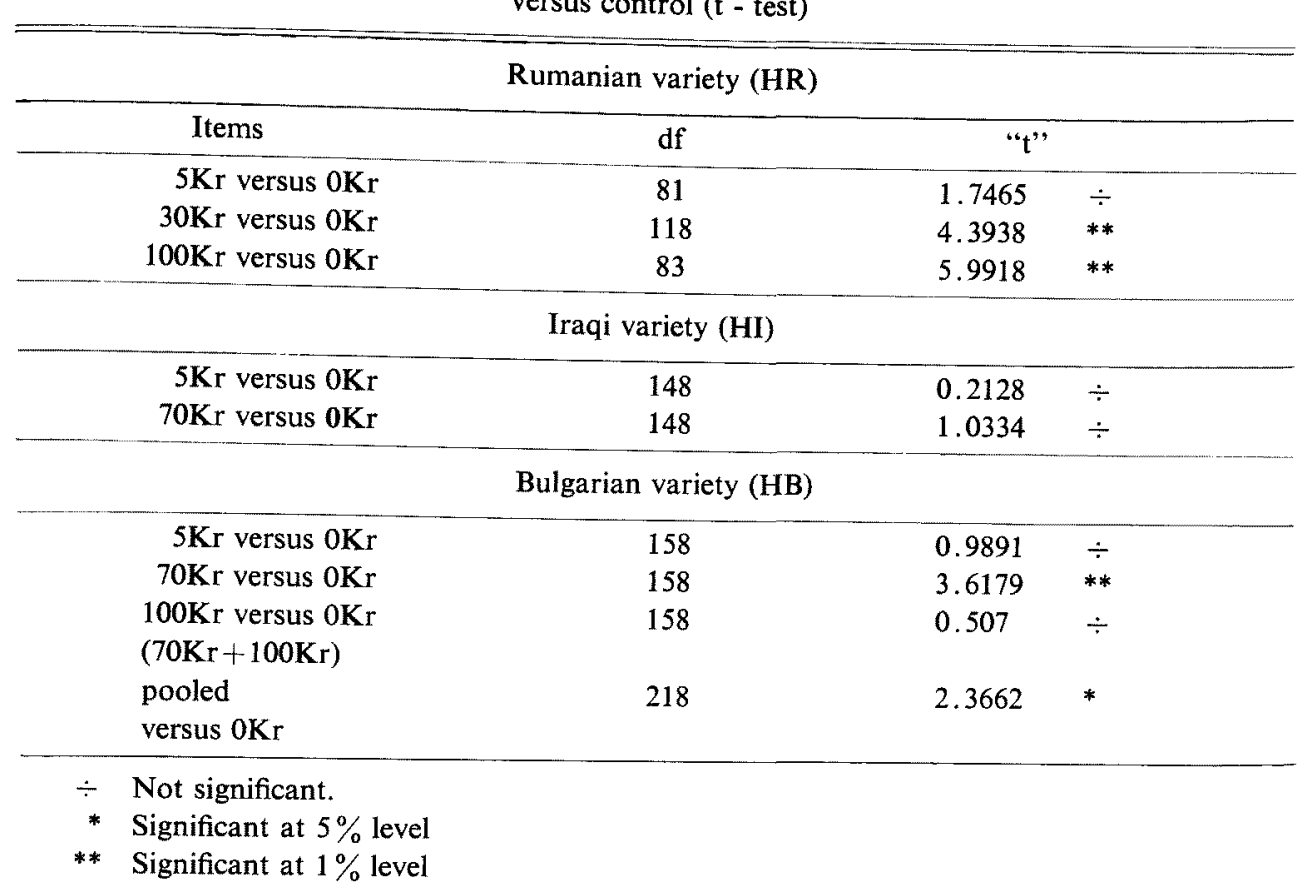

clearly demonstrated by the frequency distribution histograms (Fig. 4) of the irradiated populations which show skewness towards the lower values. This is very distinct in HR at high doses.

Frequency distributions of the numbers of chiasmata per bivalent (Table 3) clearly show, in the variety $H R$, a shift from a maximum number of bivalents with two chiasmata in the control and at $5 \mathrm{Kr}$, to a maximum with one chiasma at high doses $(30$ and $100 \mathrm{Kr}$ ); also the very few bivalents with three chiasmata have disappeared at $100 \mathrm{Kr}$. Although no such shift has been noticed in HI, the number of bivalents with two chiasmata which slightly exceeds those with one chiasma in the control, levelled off in the irradiated material. The HB variety with maximum class interval of one chiasma per bivalent already in the control, showed at pooled high doses, an increase in the number of bivalents within this category.

Calculation of the two components of variance (between nuclei and within nuclei) and the variance ratio (Table 1) seemed to show positive correlation of chiasma frequencies between bivalents, in both controls and irradiated material, except in only two cases where negative correlation is found. However, these correlations are not significant in most of the cases, indicating a lack of correlation. This point will be discussed.

\section{Discussion}

There is no doubt evidence for varietal differences in chiasma frequency within a species, with regard to the mean number per nucleus and the distribution 
between nuclei and within nuclei in the control material. Such differences can be regarded as inherent varietal differences or they can be attributed to differences in environmental conditions. Since all varieties were grown in the same field and with randomized distribution, the second possibility is ruled out.

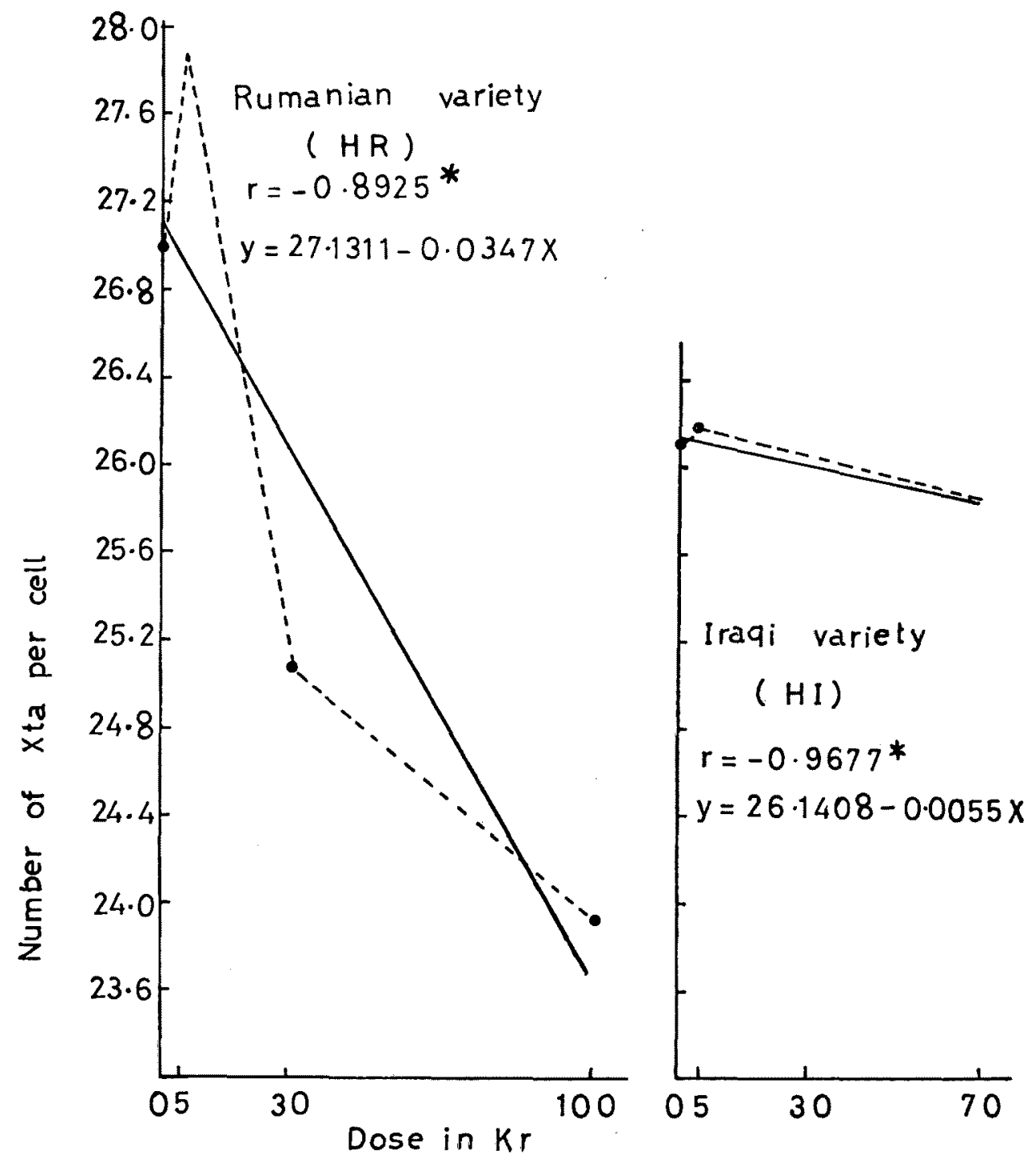

Fig. 5. Regression of chiasma frequency on dose of two varieties of $H$. annuus.

Chiasma frequency is a genetically controlled character (Rees 1955a, Rees and Thompson 1956, 1958, Sun and Rees 1964, Gale and Rees 1970). The HI control showed a small internuclear variance (Table 1). It has been pointed out in rye (Rees 1955b) that whatever the factors causing the variation between 
plants, the amount of variation measured as the variance is greater in the homozygous line than the heretozygous. Although normal sunflower populations outbreed and hence comprise genotypes which are partially heterozygous, the different behaviour of this variety could be related to a different degree of hybridity of the genotypes. The observation in this variety of single-stemmed plants among the usually branched ones, is an indication of this hybridity. The small internuclear variance could be a reflection of the great developmental stability or homeostasis in this variety with respect to chiasma frequency, as has been suggested for a heterozygous $F_{1}$ of rye (Rees and Thompson 1956). Larner (Larner 1954) in his survey of genetic homeostasis reached the conclusion that heterozygosity reduces variability around the adaptive mean value of a character in cross-fertilized species. This relationship between heterozygosity and variation has been explained by statement (Robertson and Reeve 1952) that more heterozygous individuals will carry a greater diversity of alleles, and these are likely to endow them with a greater biochemical versatility in development. This will lead to heterosis and also to a reduced sensitivity to environmental variation.

The lack of correlation between bivalents in the controls and in the irradiated material is not unusual. Different types of correlation have been reported by many workers in different organisms. Mather (Mather 1936) in his survey of 27 species and hybrids comprising certain insects and flowering plants, reported positive correlations in a few cases and this was attributed to environmental effects or to mixed material. Negatively correlated chiasma frequencies occurred more often, but not universally. Some species failed to show any correlation while others showed them in some individuals only or within groups of bivalents. On the basis of these observations Mather proposed his "hypothesis of competition" which suggests that the bivalents within a nucleus must compete for a limited number of chiasmata. Since the publication of this report by Mather, many workers have claimed different types of correlation between different bivalents of the nucleus. In Vicia faba (Rowlands 1958) negative, positive, or no correlation were all found. In Phalaris canariensis and P. minor there was no correlation (Prasad and Godward 1969).

Elliott (Elliott 1958) working on the effect of temperature on chiasma frequency in Endymion non-scriptus found different types of correlation associated with the difference in internuclear variance without any change in the inherent variance. When he analysed the behaviour of the different types of bivalents in individual plants which had shown correlation in previous analysis, he found that bivalents of an intermediate size which had formed from chromosomes with nearly equal arms and whose chiasma frequency of each arm is about one, had the lowest variance. Therefore he suggested that occurrence of correlation between the bivalents of the nucleus is more dependent on the behaviour of the long and short chromosomes than on those of intermediate size. This finding by Elliott is clearly an indication of the part played by the karyotype in controlling interchromosomal relationship.

Basak and Jain (Basak and Jain 1963) working on Delphinium ajacis demonstrated invariably negative correlations. When classifying the pollen mother cells 
of each plant into two groups showing high and low chiasma frequency, they found that the " $r$ " value is greater in cells which have the higher number of chiasmata. On the basis of these results, they put forward a suggestion that the total chiasma frequency of a cell can be partitioned into two components. The autonomous component in which the different bivalents are independent of one another, and the correlated component which is the remainder after the autonomous fraction is accounted for. The relative magnitudes of these two components determine the type of correlation. This implies that the cells having a lower chiasma frequency will have most of the chiasmata formed autonomously and only a few or none formed in a correlated way. Other cells in the same plant having a higher chiasma frequency should have a larger correlated fraction since the autonomous fraction remains unchanged in a plant. Khamankar and Jain (Khamankar and Jain 1965) in Chrysanthemum carinatum, a species with a symmetrical karyotype, found either no correlation, or positive correlation. They based their interpretation on the above suggestion of Basak and Jain. They took the argument a step further and emphasised the role of the karyotype in determining the relative magnitudes of the two components on the chiasma frequency in the cells. Beside the genotype which is of prime importance in determining the chromosomal relations, they stated that in a genus like Chrysanthemum with mostly median or sub-median centromeres, it is expected that a larger proportion of the chiasma frequency in the cell will be due to chiasmata formed in an autonomous way, since chromosomes with median or sub-median centromeres are better adapted to have a minimum of two chiasmata than chromosomes of the same length having sub-terminal centromeres. Similar results were obtained in Pisum sativum (Joshi and Chauhan 1973) confirming the Basak and Jain hypothesis.

The persent results in sunflower are also in the same line, and the positive correlations or no correlations observed could be associated with the symmetrical karyotype it possesses. Fig. 1 shows the similarity in size of the chromosomes mostly with median or sub-median centromeres. The two exceptional cases of negative correlation (Table 1) were found to be associated with relatively high chiasma frequency. The mean chiasma frequency per nucleus at $5 \mathrm{Kr}$, is the highest in the HR variety, similarly the mean of the HI control is high.

The present finding is also in agreement with that of Lamm (Lamm 1936) who has stated that inbred rye with a low chiasma frequency fails to show competition between bivalents, whereas ordinary rye with a higher chiasma frequency shows it.

That chiasma frequency is reduced by radiation is clear from the data (Figs. 3 and 5). It is reduced much more in the variety (HR) than in the other two, both of which show similarity. The variety in which the greatest reduction was obtained, had no survival of the inflorescence apex at $100 \mathrm{Kr}$ that would have produced the main head; results were scored from lateral heads. It can hardly be doubted that a much greater effect would have been seen in the main head. Both other varieties which showed lesser reductions, were able to produce main heads from which the data were obtained. These facts must reinforce the 
conclusion concerning the varietal response of $\mathrm{HR}$, in regard to chiasma frequency.

The present finding of reduced chiasma frequency in irradiated material is in agreement with nearly all previous reports on chiasma frequency following seed irradiation. The reduction of chiasma frequency could be attributed to the failure of pairing on account of structural changes produced in the chromosomes in the cell or cells responsible for the formation of the inflorescences at the time of seed irradiation (Prasad and Godward 1969). There is no adequate cytological evidence in the present material of gross structural changes of the chromosomes persisting to meiosis, since the frequency of the pollen mother cells showing aberrations in the irradiated populations did not much exceed their frequencies in the controls. A few exceptional individuals were completely abnormal and they were not suitable for chiasma scoring. Possibly most of the initial load of chromosomal aberrations has been eliminated from the apical meristem through diplontic selection, particularly in a plant like sunflower which has to grow at least one metre before the stage of sporogenesis is reached. This substantiated by the morphological results (not reported here) which show that the number of original apices which has remained viable and produced flowers was inversely proportional to the severity of the treatment.

Jain and Basak (Jain and Basak 1965) in Delphinium, have suggested that reduction in chiasma frequency after irradiation could be due to cryptic structural changes in some of the chromosomes which restrict pairing and induce univalents, hence reduce the frequency of chiasmata. Since seventeen bivalents were always observed, the reduction of chiasma frequency in the present study is certainly not due to failure of pairing in some chromosomes. Possibly cryptic structural changes such as minute deletions or small inversions in some of the chromosomes in the embryonic initials or initial which had survived the elimination process to take part in the formation of the inflorescence, may be responsible for the failure of these segments to form chiasmata and hence reduce the frequency.

It seems to us more likely that the overall chiasma potential of the plants from irradiated sunflower seeds was reduced following changes of genetic nature. This may explain the redistribution of chiasmata on the nuclear level indicated by a decline in the inherent or (intra nuclear) variance in the irradiated populations (Table 1). Comparison of the mean chiasma frequencies and mean squares within nuclei in controls and at different doses, shows that this slight decline is approximately proportional to the slight reduction of the mean chiasma frequency per nucleus with dose.

Two mutants, one partially and the other completely asynaptic, were observed among irradiated populations and these may lend further support to the above suggestion. Such mutations may arise through changes in the genetic nature of the gene or genes controlling chiasma frequency (Gottschalk and VillalobosPietrini 1965, Riley 1966). It is difficult to imagine that changes of the same nature can occur in all the cells involved in the inflorescence formation. It is felt that some evidence is obtained indicating that a single embryonic initial in some cases if not in all, could be responsible for the reorganization of the meristem after radiation injuries, ultimately taking part in the formation of the inflorescence 
in sunflower. This evidence is based on the observation of abnormalities in the $M_{1}$ generation which, when seen in a single floret, can also be seen in all the florets from the same inflorescence. Asynaptic behaviour also was found in all the florets which belonged to the same flower head.

\section{Summary}

Chiasma frequencies were determined following seed irradiation of three varieties of $H$. annuus. Histograms of chiasma frequencies between nuclei, show differences between the controls of the three varieties studied. Differing varietal response to radiation was indicated at high doses with a marked reduction in chiasma frequency with dose in one variety and a tendency in this direction in the two others, as shown by the slopes of the regression lines for Xta on dose. Reduction in the mean chiasma frequency is found to be associated with decline in the mean squares within nuclei. There is a lack of correlation between different bivalents of the nucleus both in the control and irradiated material and this, as in other plants, is found to be associated with the symmetrical nature of the karyotype in this plant.

\section{Bibliography}

Basak, S. L. and Jain, H. K. 1968. Autonomous and interrelated formation of chiasmata in Delphinium chromosomes. Chromosoma 13: 577-587.

Darlington, C. D. and La Cour, L. F. 1953. The classification of radiation effects at meiosis. Heredity 68 supp. $41-55$.

Eliott, C. G. 1958. Environmental effects on the distribution of chiasmata among nuclei and bivalents and correlation between bivalents. Heredity 12: 429-439.

Gale, M. D. and Rees, H. 1970. Genes controlling chiasma frequency in Hordeum. Heredity 25: 393-410.

Georgieva-Todorova, Y. 1972. Cytogenetic study of interspecies hybrids $H$. annuus $\times H$. ruderalis. Proceedings of the 5th International Sunflower Conference : 231-233.

Gottschalk, W. and Villalobos-Pietrini, R. 1965. The influence of mutant genes on chiasma formation in Pisum sativum. Cytologia 30: 88-97.

Jain, H. K. and Basak, S. L. 1965. Experimental modification of chiasma distribution in Delphinium. Indian Journal of Genetics and Plant Breeding 25: 14-23.

Joshi, M. C. and Chauhan, K. P. S. 1973. Internuclear distribution of chiasmata in normal diploids and interchange heterozygous of Pisum sativum L. Cytologia 38: 417-424.

Khamankar, Y. G. and Jain, H. K. 1965. Karyotype and the control of interchromosome distribution of chiasmata. Indian Journal of Genetics and Plant Breeding 25: (3): 353-359.

Lamm, R. 1936. Cytological studies on inbred rye. Hereditas 22: 217-240.

Larner, I. M. 1954. Genetic Homeostasis. Edinburgh, Oliver and Bore.

Lawrence, C.S. 1961. The effect of radiation on chiasma formation in Tradescantia. Rad. Bot. 1: 92-96.

Lawrence, C. W. 1961. The effect of the irradiation of different stages in microsporogenesis on chiasma frequency. Heredity 16: 83-89.

Marquardt, H. 1951. Die Wirkung der Röntgenstrahlen auf die Chiasmafrequenz in der Meiosis von Vicia faba. Chromosoma 4: 232-238.

Mather, K. 1934. The behaviour of meiotic chromosomes after x-irradiation. Hereditas 19: 303-322. 
Mather, K. 1936. Competition between bivalents during chiasma formation. Proc. Roy. Soc. (London) Ser. B. 120, 208-227.

- 1943. Statistical analysis in biology. : 171-175.

- and Lamm, R. 1935. The negative correlation of chiasma frequencies. Hereditas 20: 65-70.

Prasad, A. B. and Godward, M. B. E. 1969. Comparison of the developmental response of diploid and tetraploid Phalaris following irradiation of the dry seed II. Distribution of chiasmata between and within nuclei. Rad. Bot. 9: 159-166.

Ramulu, K. S. 1971. Effects of ionizing radiation and chemical mutagens on chiasma frequency in Sorghum. Cytologia 36: 543-551.

- 1973. A comparison on the effects of radiation and chemical mutagens on chromosome association and chiasma frequency in diploid Sorghum. Cytologia 38: 615-621.

Rees, H. 1955a. Genotypic control of chromosome behaviour in rye I. Inbred lines. Heredity 9: 93-116.

- 1955b. Heterosis in chromosome behaviour. Proc. Roy. Soc. 144: 150-159.

- and Thompson, J. B. 1956. Genotypic control of chromosome behaviour in rye III. Chiasma frequency in homozygotes and heterozygotes. Heredity 10: 409-424.

- and - 1958. Genotypic control of chromosome behaviour in rye V. The distribution pattern of chiasmata between pollen mother cells. Heredity 12: 101-111.

Riley, R. 1966. Induced mutation affecting the control of meiotic chromosome pairing in Triticum aestivum. Nature 211: 368-369.

Robertson, F.W. and Reeve, E. C. R. 1952. Heterozygosity, environmental variation and heterosis. Nature 170: 286.

Rowlands, D. G. 1958. The control of chiasma frequency in Vicia faba. Chromosoma 9: 176-184.

Sinha, S. S. and Godward, M. B. E. 1969. Radiation studies in Lens culinaris: Distribution of chiasmata between nuclei and within nuclei in irradiated and non-irradiated populations. Cytologia 34: 45-51.

Sun, S. and Rees, H. 1964. Genotypic control of chromosome behaviour in rye VII. Unadaptive heterozygotes. Heredity 19: 357-367.

Sybenga, J. 1960. The effect of gamma rays on frequency and localisation of chiasmata in Crotalaria intermedia. Rad. Res. (abstract) 12: 478. 